\title{
O LEGADO DA PARTILHA DA ÍNDIA E PAQUISTÃO VIOLÊNCIA CONTRA MUÇULMANOS NA ÍNDIA PÓS-COLONIAL
}

\author{
THE LEGACY OF PARTITION \\ VIOLENCE AGAINST MUSLIMS IN POSTCOLONIAL INDIA
}

\author{
Mariana Faiad B. Alves ${ }^{1}$
}

\begin{abstract}
Resumo: Este artigo busca analisar a violência contra Muçulmanos na Índia como um dos principais legados da Partilha da Índia e Paquistão. 0 artigo irá discutir a violência religiosa em um duplo papel, como causa e consequência de decisões políticas. Serão analisadas as políticas em torno da Partilha, e o papel da violência religiosa nas decisões em curso no período. Em seguida, o artigo irá analisar a violência como ferramenta da destruição da mesquita em Ayodhya, e o massacre em Gujarat, como apelo final na corrida ao poder dos grupos extremistas hindus. Por fim, irá discorrer sobre a representação dos muçulmanos na Índia contemporânea.
\end{abstract}

Palavras-chave: Partilha, Ayodhya, Gujarat, Violência, Muçulmanos.

\begin{abstract}
This article aims to analyse the violence against Muslims in India as one of the main legacy of the Partition. It will discuss religious, or communal, violence in a double stance, as cause and as consequences of political decisions. It will analyse the politics of the Partition and the role of communal violence in the politics of that period. Thereafter, it will move to an analysis of communal violence as a mechanism in the destruction of the Babri masjid in Ayodhya, and the pogrom of Gujarat as a final appeal on the run for power from Hindu extremists. At last, it will look at the discourses on the representation of the Muslims in contemporary India.
\end{abstract}

Key-words: Partition, Ayodhya, Gujarat, Violence, Muslims

\section{Introdução}

A Índia possui a terceira maior população muçulmana do mundo, atrás da Indonésia e do Paquistão. A população muçulmana na Índia gira em torno dos 172 milhões segundo o censo de 2011, correspondendo a 14,2 por cento da população do país. A Índia é o país com a maior minoria muçulmana do mundo.

A chegada dos primeiros muçulmanos árabes ocorreu no início do século VII, em um histórico de confrontos e saques, sem fincar domínio político e territorial. A Índia foi formalmente governada por muçulmanos, não árabes, mas de origem turca, no século XVI, no que é conhecido por Império Mughal, estabelecido após o general Babur vencer a batalha de Panipat em 1526.

\footnotetext{
${ }^{1}$ Possui graduação em Antropologia pelo Goldsmiths College, Universidade de Londres, mestrado concluído e doutorado em andamento pelo Departamento de Sociologia da Universidade Estadual de Campinas. Foi visiting researcher no Institute for Social and Economic Change em Bangalore, Índia (2010) e no Center for Postcolonial Studies da Universidade de Londres (2015). Email: marifaiad.alves@gmail.com. Link para o Currículo Lattes: http://lattes.cnpq.br/3951073428352583.
} 
A relação entre muçulmanos e a maioria da população indiana, classificada dentro da aba geral e controversa de hindus, possui um histórico de convivência pacífica, compartilhando crenças e locais sagrados, como é o caso dos centros sufistas, braço predominante do Islã na região à época, que viabilizava interações com cultos hindus. Da mesma forma, hindus e muçulmanos se uniram em lutas contra o domínio do Império Britânico, como a primeira guerra de independência da Índia. Por outro lado, há um histórico de confrontos e batalhas, de discriminação e violência. Após séculos de convívio, as políticas em torno da formação de um Estado moderno na região foram fundamentadas no princípio de que os muçulmanos e os hindus deveriam cada qual ter o seu próprio espaço. Hindus e muçulmanos optaram pela formação de dois Estados separados (atualmente três), no evento conhecido por Partilha da Índia e Paquistão.

Este artigo pretende analisar as consequências da Partilha nas relações entre hindus e muçulmanos na Índia independente. Dentre as diversas facetas destas relações, este artigo focará nos eventos de violência religiosa e coletiva, em episódios que chamamos de tumultos sectários. Ademais, o artigo irá discorrer sobre processos de representação dos muçulmanos na Índia, argumentando que certas análises sociais desconsideram a influência da cultura muçulmana na Índia contemporânea, influenciando instituições que ignoram o papel da violência religiosa como fato constante na sociedade indiana pós-colonial.

\section{Políticas em torno da Partilha da Índia e Paquistão}

A Índia conquistou independência no dia 15 de agosto de 1947, após uma luta nacionalista de mais de três décadas. A região que estava sob domínio britânico, British Raj, foi dividida em dois Estados: a Índia e o Paquistão, no evento histórico conhecido por Partilha da Índia Britânica. O Paquistão conquistou independência no dia 14 de agosto de 1947, e a princípio era composto de duas partes separadas, o Paquistão Ocidental (atual Paquistão) e o Paquistão Oriental. Em 1971, com o apoio da então primeira ministra indiana Indira Gandhi, o Paquistão Oriental conquistou a independência, tornando-se Bangladesh.

Ainda que o Paquistão (oriental e ocidental) tenha celebrado sua independência no dia 14 de agosto de 1947, e a Índia no dia 15, as fronteiras dos novos Estados foram anunciadas no dia 17 de agosto de 1947. As fronteiras foram estabelecidas por uma comissão liderada pelo advogado britânico Cyril Radcliffe, que pouco conhecia a região, utilizando-se de mapas e materiais oriundos dos registros acumulados pelos diversos censos demográficos organizados pelos britânicos. Comunidades, famílias e propriedades foram cortadas ao meio na divisão, no que foi um período caracterizado por intensa violência e deslocamento de pessoas.

A partilha do subcontinente, e o estabelecimento de dois Estados independentes da Índia e do Paquistão (ocidental e oriental) ocorreu com uma rapidez impressionante e de forma imprevista nos anos anteriores. Foi em um intervalo de tempo curto, apenas um 
ano, entre a primeira articulação formal de demanda para um Estado soberano para os muçulmanos da região, e o estabelecimento de fato do Paquistão. E poucos previram que a divisão do território e do poder central seria acompanhada por qualquer coisa semelhante à violência desencadeada neste período.

A retirada dos britânicos da Índia foi anunciada na vitória do partido trabalhista nas eleições britânicas em julho de 1945, meio a constatação de que o estado britânico, devastado pela Segunda Guerra Mundial, não poderia mais se sustentar como potência imperial na região. Um ato do parlamento britânico propôs uma data para a transferência de poder para as mãos dos indianos, marcada para junho de 1948, que foi antecipada em um ano pelo último vice-rei para a Índia, lorde Louis Mountbatten. 0 vice-rei negociou a retirada britânica com os membros do partido do Congresso Nacional (doravante Congresso), liderados por Jawaharlal Nehru, e com os membros da Liga Muçulmana liderada por Muhammad Ali Jinnah. À época da retirada britânica, os muçulmanos representavam mais de 30 por cento da população da região.

Entre os anos de 1857 e 1858, diversas rebeliões desencadearam no que os indianos consideram a primeira Guerra de Independência da Índia, a qual é chamada, pelos britânicos, de Sepoy Mutiny. Neste período, a administração britânica na Índia era controlada pela Companhia das Índia Orientais. Sepoy é o título designado a soldados nativos, hindus e muçulmanos sobretudo, empregados a serviço da Companhia. A revolta dos sepoys uniu hindus (de diversas castas) e muçulmanos (de diversas seitas), e desencadeou uma onda de rebeliões por toda a Índia. Os motivos exatos que desencadearam esta guerra são complexos, resultantes de inúmeros fatos ocorridos no curso das relações travadas pela Companhia na Índia desde o século XVII. As consequências desta guerra levaram à dissolução da Companhia, e à posse direta da administração da Índia pela coroa britânica, na formação do British Raj. A rainha Vitória foi a primeira Imperatriz da Índia.

A Guerra, portanto, resultou em mudanças radicais nas políticas da administração colonial. Significou, principalmente, o fim das políticas de anexação de terra, e o início de uma política de alianças com as elites locais, e com os principados autônomos (principados muçulmanos, que mantiveram soberania após o declínio do Império Mughal, e principados hindus), a fim de evitar outras rebeliões e de cercear a crescente onda nacionalista. 0 Raj desenvolveu o que ficou conhecido por Divide and Rule Policy - dividir para governar - que, nas palavras do funcionário administrativo britânico sir John Strachery, buscava prevenir o crescimento de quaisquer sentimentos unificados de cunho nacionalista (Stewart 1951: 49). Na formação no exército, e nas políticas mais diretas com a população, essa política significava enfatizar as diferenças de casta e de religião com o intuito de prevenir a ascensão de um nacionalismo unificado, tendo em vista a guerra dos Sepoys. A política do divide and rule atuou em primeiro lugar no exército, com o intuito de formar regimentos distintos compostos por grupos religiosos distintos, assim como regimentos em torno de critérios de castas. Em seguida, o Raj passou a investir em um Censo demográfico que categorizava a população por casta e religião, formando eleitorados específicos. 
Para Gyan Pandey (1990), justificar a violência sectária desencadeada pelos processos que levaram à independência da Índia e do Paquistão como fruto de desavenças entre as duas maiores comunidades religiosas da região não passava de um desdobramento discursivo da política do divide and rule. Nesta perspectiva, a violência em curso no período colonial era muito mais complexa, envolvendo as relações particulares travadas entre os britânicos e os respectivos líderes religiosos, sobretudo no que se refere ao acesso à terra e a postos de trabalho dentro da administração colonial, com o intuito de coibir qualquer forma de rebelião. Com isso, as hostilidades entre as comunidades religiosas são um desdobramento direto das políticas britânicas que culminaram na Partilha: a concretização da política do dividir para governar. De fato, a primeira grande onda de violência no período colonial foi o massacre de Cawnpore, liderada pelos sepoys - hindus e muçulmanos unidos - com um salto de mais de 120 vítimas fatais, a maioria britânica.

No ano de 1905, o então vice-rei da Índia britânica, lorde Curzon, dividiu a maior província administrativa da região, a província de Bengala, cuja capital Calcutá era a sede do Raj. Por um Ato parlamentar, Curzon dividiu a península de Bengala em uma parte ocidental, de maioria hindu, com capital em Calcutá, e em uma parte oriental, com maioria muçulmana, com capital em Dhaka (atual capital de Bangladesh). A elite bengali da parcela ocidental, os bhadralok, protestou de forma abrupta a possível perda de territórios. Por ter sido uma partilha na região mais importante do império, a rebelião hindu reverberou por toda a Índia. Foi nesse momento que os muçulmanos se organizaram e fundaram a Liga Muçulmana - All-India Muslim League, em Dhaka. Dada a disparidade de protestos contra a partilha da província de bengala, a proposta não se concretizou, Curzon foi exonerado do posto e retornou à Inglaterra. Mas parte considerável da elite muçulmana aderiu a ideia, e mesmo com o fracasso da partilha de Bengala, surgiu um movimento em torno da formação de estados federativos muçulmanos dentro da união indiana. A política britânica do divide and rule já havia construído um modelo de participação política voltado a eleitorados específicos, com votos proporcionais. A liga Muçulmana passou a reivindicar um eleitorado muçulmano específico nas regiões de maioria muçulmana para compor o quadro administrativo da Índia independente.

O estado do Punjab foi uma peça crucial nos jogos de interesse à época da independência. O Punjab na Índia colonial era um estado de maioria muçulmana, e também era o local onde vivia a maioria dos Sikh, cujos interesses políticos estavam alinhados com a maioria hindu, representada sobretudo pelo partido do Congresso ${ }^{2}$. Foi no Punjab em 1924, que pela primeira vez a solução para a soberania contestada na região foi proposta pelo líder nacionalista hindu Lala Lajpat Rai. Ele propôs uma partilha da província do Punjab, nos moldes previstos por Curzon em Bengala, para manter o princípio do governo da maioria efetivo; Rai discordava da proposta de que os estados de maioria muçulmana seriam governados pelos muçulmanos, sobretudo das consequências deste governo para a população hindu e sikh. Sua proposta de criação de duas províncias dominadas

${ }^{2} 0$ partido do Congresso foi peça chave na luta pela independência, com lideranças importantes como Jawaharlal Nehru e Gandhi. O Congresso não fora fundado como um partido hindu; diversas lideranças muçulmanas compunham o quadro do partido. Foi o partido dominante na Índia pós-colonial até a ascensão do partido nacionalista hindu BJP em meados da década de 1980. 
por muçulmanos - efetivamente a metade do Punjab e a metade de Bengala - deveriam permanecer parte da Índia de maioria hindu.

Mas foi Muhammad Iqbal, líder muçulmano do Punjab, que transformou os parâmetros do debate. Iqbal foi o primeiro a levar para a arena política um discurso religioso que criticava a proposta de Estado secular, articulada pelo partido do Congresso. O discurso veiculado por Iqbal rejeitava a ideia da separação entre os domínios materiais e espirituais na articulação de um Estado independente. Para ele, estes domínios não eram distintos no Islã, uma vez que a natureza da ação, mesmo secular em sua natureza, é determinada pela atitude da mente do agente que a pratica. Rejeitando os ideais pósiluministas de uma relação de oposição binária entre o mundo material e espiritual como duas realidades distintas, para Iqbal a unidade dos seres humanos com o Islã precipita uma unidade singular. 0 princípio tauhid, que molda a submissão dos muçulmanos a Allah, é regulado por princípios de igualdade, solidariedade e liberdade. A missão de um Estado, na perspectiva islâmica de Iqbal, era a de possibilitar a transformação destes princípios ideais em realidade. Para Iqbal, o Estado no Islã é uma teocracia. Iqbal, porém, não discutia a ideia de um Paquistão independente, ele buscava negociar como os muçulmanos indianos iriam sobrevier, quais os mecanismos constitucionais que seriam operantes na sobrevivência cultural da minoria religiosa.

Meio a este debate, a demanda inicial da Liga Muçulmana era a de criar um estado com maioria muçulmana dentro da federação de estados que viria a compor a Índia independente. As províncias com maioria muçulmana eram localizadas na região noroeste da Índia britânica (províncias do Baluchistão, Sindh, North-Western Frontier, Caxemira e Punjab) e na região nordeste (província de Bengala). A proposta da Liga era que estas províncias constituíssem dois blocos fisicamente separados, mas unidos administrativamente, e com poucos ajustes - se necessário - nas fronteiras já existentes.

Paquistão significa "terra dos puros" em persa, e faz um acrônimo com as regiões de maioria muçulmana do P (punjab), K (kashmir) e S (sindh). O Paquistão foi pensado para ser um estado com maioria muçulmana, para fazer um balanço com o Hindustão de maioria hindu. A demanda pelo Paquistão, na visão da Liga Muçulmana visava uma liberdade real para ambos os muçulmanos e hindus, o melhor acordo para as minorias e justiça para todos os oprimidos. "Dividir para unir" era o lema da Liga Muçulmana; uma vez que os muçulmanos estivessem livres e seguros no Paquistão e os hindus no Hindustão, os dois poderiam se unir em muitas áreas, como comunicações, defesa, relações internacionais, direitos civis. A proposta de Jinnah, líder da Liga, era a de soberania compartilhada, por meio de uma federação.

O plano inicial de divisão das províncias buscava uma alteração mínima na distribuição demográfica dos muçulmanos e hindus, e na vida das comunidades e nos arranjos sociais, locais e econômicos locais. O Paquistão, como previsto por Jinnah não visava qualquer forma de desenraizamento de associações, qualquer que fossem, nem laços existentes há muitas gerações entre as populações das províncias de maioria hindu com as províncias de maioria muçulmana. Este era o plano e a ideia presente no ano de 1942. 
Jinnah e a Liga eram a favor da integridade, e não da divisão, das províncias do Punjab e de Bengala ao integrarem o Paquistão (ainda como parte da federação indiana). Jawaharlal Nehru, então líder do partido do Congresso, ao visitar o Punjab em março de 1945 afirmou que federações são melhores do que partilhas. E foram convocadas eleições para decidir o destino das províncias.

No mês de maio de 1946, um acordo foi assinado entre o partido do Congresso e a Liga no Cabinet Mission Plan para estabelecer uma federação frouxa na Índia, com as províncias de maioria muçulmana no Noroeste e no Nordeste agrupadas em duas unidades federativas, e o resto da Índia agrupada em uma terceira unidade; e uma provisão constitucional para rever este acordo em um período de dez anos. 0 Cabinet Mission foi uma tentativa britânica de orquestrar um acordo entre o partido do Congresso e a Liga Muçulmana. No tratado de 16 de maio de 1946, o acordo girava em torno de uma confederação com os estados de maioria muçulmana e o restante de maioria hindu.

Mas os grupos não foram capazes de chegar a um acordo de como se daria o balanço de poderes entre os dois blocos da federação. 0 colapso do acordo, porém, se deu devido a suspeitas e reservas contínuas por meio de líderes tanto do Congresso como da Liga. Os líderes do partido do Congresso, especialmente na figura de Vallabhbhai Patel, receavam o possível agrupamento de províncias e estados em unidades regionais, com os muçulmanos possuindo maioria em duas regiões. Do colapso deste acordo, a proposta da Partilha em dois Estados soberanos foi proposta como única alternativa possível, dada as circunstancias. Com isso, em 16 de junho de 1946, o plano de dividir a Índia e o Paquistão em dois Estados independentes é oficialmente estabelecido, e colocado em votação em eleições regionais convocadas pelos dois partidos. No plano da Partilha, as províncias do Punjab e de Bengala seriam divididas ao meio, por serem províncias de maioria muçulmana, com grande população hindu e sikh.

Em 16 de agosto de 1946, Jinnah lançou, em Calcutá, uma campanha de ação direta para a formação do Paquistão. Muçulmanos de Calcutá pararam suas atividades e saíram em protestos pelas ruas centrais da cidade. Grupos de muçulmanos forçaram os comerciantes hindus a fecharem seus negócios; e os hindus responderam bloqueando o avanço do protesto que caminhava em direção ao centro da cidade. Deste confronto, tumultos sectários violentos ocorreram, contabilizando mais de 5 mil mortes em quatro dias de violência (Hansen 2002); 10 mil mortes de acordo com uma segunda fonte (Sengupta 2005). Este evento, conhecido por The Great Calcutta Killings de agosto de 1946 foi uma consequência direta da chamada de Jinnah pelo Paquistão. A violência desencadeada contra hindus ocorreu dentro de um governo liderado pela Liga Muçulmana na província de Bengala (Khosla 1989 [1949]). A violência de Calcutá foi replicada em outras partes do país tornando-se um dos principais fatores que contribuíram para que o partido do Congresso e os Britânicos aceitassem a proposta de um Estado de maioria muçulmana (Brass 2003: 73).

O papel da Liga Muçulmana em orquestrar esses tumultos sectários foi crucial na intenção de armar e transportar os grupos protestantes. Este foi um tumulto sectário 
marcante, pois desencadeou as primeiras ondas de emigração deixando Calcutá rumo a Dhaka, que viria a ser a capital do Paquistão Oriental.

A proposta da Partilha completa da Índia britânica em dois Estados independentes para responder as demandas de comunidades religiosas específicas reforçou a ideia de que as minorias não mais pertenciam nas terras ora designadas aos muçulmanos ou aos hindus. Tal atitude irá levar, nos meses que seguiram o estabelecimento da Índia e do Paquistão, ao deslocamento de praticamente todos os hindus e sikhs do Punjab ocidental, assim como dos muçulmanos do Punjab oriental, e o mesmo na província de Bengala.

Centenas de milhares de pessoas estavam nas ruas do Punjab nos dias da Partilha oficial; massacres e tantas outras partilhas as quais as pessoas teriam que lidar por muito tempo, como a separação de famílias, deslocações de seus lugares de origem, imigração em massa e, sobretudo, a legitimação da violência religiosa pela construção de um Estado que deveria prover a todos os muçulmanos cujas consequências são sentidas até hoje. Em agosto de 1947, mais de 600 mil muçulmanos refugiados da Índia cruzaram a fronteira com o Paquistão somente pela cidade de Amritsar, no Punjab, ao passo que mais de 500 mil hindus cruzaram do Paquistão para a Índia somente na mesma cidade ${ }^{3}$.

A maior contradição da criação do Paquistão é que essa divisão não satisfez os interesses dos próprios muçulmanos que lutaram para sua criação. A contradição se dá no conflito de noções diferentes do Paquistão - um Estado para acolher todos os muçulmanos da Índia, versus a ideia de um estado federativo que iria proteger todos os muçulmanos indianos, que poderiam ficar onde quer que estivessem no subcontinente. Não havia evidencias claras de como os muçulmanos espalhados por todo o subcontinente, divididos por classe, seitas, interesses regionais e línguas, se tornariam parte de um país separado; tampouco era claro exatamente onde esse novo Estado do Paquistão efetivamente seria.

Com a Partilha, a população muçulmana na Índia caiu de 30 por cento para 12 . A esmagadora maioria da elite muçulmana migrou para o Paquistão. Estimativas apontam que em 1947 uma média de 10 a 12 milhões de pessoas cruzaram as fronteiras da Índia e do Paquistão (ocidental e oriental), o que levou comentadores a descrever este evento como a maior migração da História até então (Brass 2003). Ainda é extremamente difícil chegar a um consenso sobre o número de pessoas que morreram como consequência da violência nos processos que desencadearam na Partilha, seja no evento em si, como nos campos de deslocados internos e refugiados em funcionamento anos após o evento. Estimativas giram em torno de 200 mil por um lado, a 1,5 milhão de vítimas fatais. 0 consenso é trabalhar com 500 mil. A estimativa mais baixa é certamente alta o suficiente para sugerir a magnitude do desastre, tendo em vista que o período em questão era um período de "paz": não havia guerra declarada entre o Estado da Índia e do Paquistão, ou entre ambos e o Reino Unido. A formação da Índia, com Nehru no posto de Primeiro Ministro, e do Paquistão, com Jinnah como Primeiro Ministro, foi negociada com os britânicos, após embates e lutas; não houve uma guerra de independência, como ocorreu

\footnotetext{
${ }^{3}$ De acordo com o Jornal London Times de 30 de agosto de 1947. Atualmente o jornal se chama The Times: thetimes.co.uk/archives
} 
em outras colônias britânicas. Nos últimos dias do Raj, a violência não fora disseminada somente como consequência da Partilha, mas ao contrário, a violência foi um dos principais mecanismos a criar as condições para a Partilha (Rai 1965; Brass 2003), pois apontava, e afirmava, a impossibilidade de convivência entre as comunidades hindus e muçulmanas. A violência instigada pelos líderes políticos era parte integrante dos processos políticos, com potencial de ser utilizada novamente no futuro quando outros mecanismos políticos falharem. A violência passou a ser uma peça fundamental na construção das políticas de identidade na Índia pós-colonial.

\section{Babri Masjid versus Templo de Rama}

A violência como mecanismo integrante das políticas de identidade foi mobilizada no caso emblemático da disputa de Ayodhya.

Ramayana, poema épico extremamente relevante nas práticas do hinduísmo contemporâneo, narra a história do Lorde Rama, rei de Ayodhya. Segundo as narrativas do épico, a esposa de Rama, Sita, fora abduzida por Ravana, rei demoníaco da ilha de Lanka. Rama, com auxílio do deus-macaco Hanuman, construiu uma ponte que ligava o sul da Índia à ilha de Lanka, destruiu Ravana, e recuperou sua esposa.

Reivindicar uma identidade unicamente hindu à Ayodhya fez com que a cidade se tornasse um local de disputas. Além de ser berço de nascimento de Rama, a cidade também é um importante centro de peregrinação muçulmana. Foi exatamente em Ayodhya que o primeiro lider Mughal, o general Babur, construiu uma mesquita - Babri masjid - no centro da cidade. A mesquita foi construída por volta do ano de 1528, e foi um dos primeiros monumentos construídos pela dinastia Mughal.

A reivindicação de Ayodhya como centro hindu é fruto de uma crescente propaganda nacionalista. Enfraquecido por mais de um século, o nacionalismo hindu adquiriu força política desde a metade da década de 1980, por meio do partido Bharatiya Janata (BJP). O sucesso político do BJP depende de suas alianças com dois movimentos nacionalistas hindus, o Vishva Hindu Parishad (VHP), organização de líderes religiosos hindus, e a organização não-governamental Rashtriya Swayamsevak Sangh (RSS), fundada em 1925 (Veer 1994: 01). Essas alianças possibilitam o uso do discurso religioso e o uso de rituais religiosos na arena política. A agenda política do BJP não pode ser separada da agenda do VHP e da RSS. Há uma coordenação de rituais, agitações e manobras políticas do alto comando do BJP, do RSS e do VHP, que se misturam significativamente. O VHP, a RSS e o BJP não são meras organizações nacionalistas hindus, desconectadas da maioria da sociedade. O VHP e o RSS estão presentes em todos os estados da Índia, e o BJP atualmente está na liderança do governo indiano: Narendra Modi, atual primeiro ministro da Índia, passou a infância e adolescência na sede do RSS em Mumbai.

Em sua concepção de hinduísmo, os nacionalistas hindus utilizam dois significados para hinduísmo: como cultura e como religião. Hindu não é o nome de uma fé religiosa, 
como muçulmano e cristão; hindu denota cultura e vida nacional na Índia, diz Sheshadri (apud Varshney 2002: 65), um dos principais líderes atuais do RSS. Nesta perspectiva, os líderes do BJP não separam a religião da política; ao contrário, a religião é mobilizada constantemente e em diversas formas, como fundamentação e como veículo principal da divulgação de suas propostas políticas.

Savakar foi o fundador ideológico do nacionalismo hindu no que ele chamou de filosofia política Hindutva, que veicula a crença de que a identidade hindu é inseparável da identidade indiana. Os teóricos do movimento se apoiam em fatos culturais e históricos da tradição hindu, cuja origem remete a praticamente três milênios (ao menos até os Veda), e buscam, com isso, afirmar que praticamente toda a cultura indiana tem origem na marca histórica das práticas e pensamentos hindus (Sen, 2005: 53). 0 hinduísmo, portanto, seria a fonte da identidade indiana - e sozinho é capaz de prover coesão nacional. Para Savarkar, um hindu se define por considerar a terra que vai do rio Indus aos mares como terra pátria, assim como terra sagrada (apud Johnson \& Johnson 2008: 2564). Nesta perspectiva a definição de quem é hindu é territorial (refere-se a terras do rio Indus chegando aos dois mares), é genealógica (refere-se a uma pátria), assim como religiosa (refere-se a uma terra santa). Nestes critérios, todas as religiões indianas outras que o hinduísmo, seja o siquismo, jainismo e o budismo, preenchem os requisitos identitários hindus. Cristãos, judeus, parsis e muçulmanos podem preencher somente um ou dois destes critérios, pois a Índia não é a terra sagrada de suas religiões.

O discurso nacionalista hindu veicula a ideia de que o general Babur, em meados do século XVI, destruiu o templo em tributo ao Lorde Rama que havia em Ayodhya. Segundo estes grupos, o general Babur construiu a mesquita nos pilares do antigo templo, exatamente no local onde Rama nasceu. Com isso, a cidade de Ayodhya acabou se tornando um local de disputas acirradas entre as duas maiores comunidades religiosas da Índia, ambas disputando o mesmo espaço como sendo representante legítimo de suas crenças.

Após a Partilha da Índia e Paquistão, o governo indiano instituiu a obrigação da presença de um guarda dentro da mesquita, com o intuito de salvaguardar a integridade do local dada a tensão que se formava entre as duas comunidades religiosas. Na noite do dia 22 para 23 de dezembro de 1949, uma imagem do Lorde Rama foi inserida na mesquita por um grupo hindu. No dia seguinte, um rumor se espalhou de que Lorde Rama aparecera em forma de imagem dentro da mesquita para reivindicar a mesquita como seu templo. Grupos muçulmanos organizaram diversos protestos contra grupos hindus, acusando-os de ter inserido uma imagem hindu dentro da mesquita, fato que fere os muçulmanos não por ser uma imagem hindu, mas por ser uma imagem em si, afinal, o Islã proíbe qualquer culto a imagens de pessoas, principalmente no interior do solo sagrado de uma mesquita. E grupos hindus agiram em contrapartida, alegando o caráter ilegítimo da construção da mesquita. Estes protestos assumiram um caráter de tumulto sectário,

\footnotetext{
${ }^{4}$ Original: "a Hindu means a person who regards this land from the Indus to the Seas as his fatherland as well as his Holyland" tradução da autora.
} 
conhecido na literatura indiana como "communal riots". 0 episódio de 1949 foi o primeiro que se tem registro de violência sectária em torno da disputa em Ayodhya.

0 ano de 1984 é emblemático nesta disputa, pois marca o início de uma campanha nacional para libertar o local de nascimento de Rama. Esta campanha é muito distinta do episódio ocorrido em 1949, que envolveu conflitos e episódios de violência entre grupos locais na região da cidade. Em 1984, o VHP organizou uma procissão, iniciada em Sitamarthi, local de nascimento de Sita, demandando que a mesquita deixasse de ficar trancada, com acesso liberado para cultos hinduístas. Em prática, essa abertura significaria que qualquer pessoa que não fosse muçulmana poderia entrar na mesquita para cultuar o lorde Rama. Este evento, porém, foi ofuscado, perdeu o impacto nacional devido ao assassinato de Indira Gandhi por um de seus guarda-costas.

As lideranças muçulmanas estavam alertas ao fato de que tentativas de converter mesquitas históricas, símbolos da identidade cultural muçulmana, em templos, era tolerada, se não incentivadas, pelo governo central. 0 primeiro ministro Rajiv Gandhi, então líder do partido do Congresso, se comprometeu em votar a favor da comunidade muçulmana na disputa de Ayodhya. Porém, apoiou a decisão judicial em 14 de fevereiro de 1986, que cedeu às demandas do VHP, determinando que o local em disputa permanecesse aberto ao público. Esta decisão desencadeou novos tumultos sectários por todo o norte do país, e em 30 de março do ano seguinte os muçulmanos organizaram, na capital Deli, o maior protesto desde a independência (Veer 1994: 03).

Em face a esta disputa, em 1986 dois grupos se formaram: a Babri Masjid Movement Coordination Commitee (BMMCC), sob liderança de Sayyid Shahabad al-Din, membro do parlamento indiano Lok Sabha, e a Babri Masjid Action Commitee (BMAC) liderada pelo advogado Zafar Yab Jilani. Porém, nenhuma destas organizações foi capaz de conter a instabilidade política. Mesmo com os esforços destas organizações em lançar campanhas nacionais, não podemos negar o fato de que a comunidade muçulmana na Índia não possui um líder carismático capaz de unir as diferentes vertentes, capaz de criar alianças entre os muçulmanos, separados por regiões e seitas por toda a Índia.

A partir de 1989, o VHP iniciou uma campanha nacional de culto aos "tijolos de Lorde Rama" pelo norte da Índia, organizando processões/passeatas para trazer tijolos sagrados para Ayodhya, que seriam usados na construção do templo a Rama. Com isso, além de visibilidade nacional, a disputa assume um novo caráter. De 1989 em diante, não se trata mais em utilizar a mesquita para o culto a Rama; a campanha passa a ser pela destruição da mesquita, e pela construção de um templo no mesmo lugar. O VHP organizou uma procissão na cidade de Bhalgapur, estado de Bihar, com o intuito de coletar tijolos sagrados e seguir à Ayodhya. No dia 24 de outubro de 1989, um grupo escoltado pela polícia, com a presença do superintendente da Polícia KS Diwivedi, passava pelo distrito de Tartapur, de maioria muçulmana, cantando slogans como "Hindi, Hindu, Hindustan, Mullah Bhago Pakistan (Índia para os hindus; mullahs vão para o Paquistão) e Babur ki auladon, bhago Pakistan ya Kabristan (Filhos de Babur saiam para o Paquistão ou para a cova) (Engeneer 1990:307). 
O estado de Bihar possui um histórico de conflitos entre as duas comunidades religiosas. Alguns dias antes da passeata chegar à cidade, rumores foram espalhados afirmando que um grupo de mais de 200 estudantes universitários hindus haviam sido assassinados por um grupo de muçulmanos, seguido de um assassinato, também por muçulmanos, de 31 rapazes hindus em frente ao Sanskrit College de Bihar. Estes rumores se provaram falsos, mas incitaram diversos tumultos sectários (People's Union for Democratic Rights Report, PUDR, 1996: 242). Uma comissão de inquérito fora instaurada para investigar as causas dos tumultos em Bhagalpur, concluindo que o estopim da violência foi desencadeado pela passeata dos tijolos de Rama, (SINHA \& HASAN apud PUDR 1996, p. 14), autuando inclusive o superintendente da polícia Dwivedi por omissão na contenção da violência. E não foi somente um embate entre muçulmanos e hindus: dados oficiais apontam para 1.070 mortes e 524 feridos, a maioria de muçulmanos em menos de uma semana de tumultos. Grupos de karsevaks chegavam de carro, ônibus e trem de diversas partes da Índia para se unir aos outros (karsevak é o nome dado às pessoas que se voluntariam pela causa religiosa hindu, e são mobilizados e financiados sobretudo pelo VHP e pela RSS). A vila de Bhagalpur foi praticamente destruída (Veer 1994: 04). 0 culto aos tijolos de Lorde Rama foi um dos maiores conflitos entre hindus e muçulmanos desde a Partilha.

Em 1990 Lal Kishan Advani, liderança do BJP, organizou um ritual que passaria por diversos estados indianos - de Somanatha, no estado de Gujarat, à Ayodhya, em Uttar Pradesh - com o intuito de finalmente construir o templo do Lorde Rama, no dia 30 de outubro de 1990. Advani, saiu em pessoa em carreata pelos estados no norte da Índia em um rath - um ônibus transformado em uma carruagem mítica, como a que lorde Krishna usara nos relatos do Bhagavda Gita.

Mulayam Singh Yadav, então governador de Uttar Pradesh pelo partido socialista Samajwadi Janata Party (SJP) afirmou que não deixaria a procissão de Advani entrar em Ayodhya, e antes do dia 30 de outubro, Advani foi preso, com o aval do primeiro ministro Vishwanatan Pratab Singh, também do SJP. A prisão de Advani não preveniu os karsevaks de continuar o rath à Ayodhya mas foram impedidos pela polícia. Vishwanatan Pratab Singh e seus aliados estavam alinhados com a tradição institucional do secularismo. Nesta perspectiva governo indiano não poderia permitir a alienação radical de sua população muçulmana com a destruição de uma mesquita construída no século XVI. É improvável que um governo liderado pelo partido do Congresso teria agido da mesma forma, pois o antecessor de VP Singh, Rajiv Gandhi, se posicionou, em mais de uma ocasião, a favor de Advani e dos hindus em Ayodhya. De qualquer forma, as ações encabeçadas por Viswanatan Pratab Singh resultaram na perda do apoio do BJP no parlamento indiano e a subsequente queda do governo de VP Singh que governou durante o curto período de dezembro de 1989, a novembro de 1990.

A queda de VP Singh marca o início da ascensão do BJP e com ele o nacionalismo hindu. Nas eleições nacionais de maio e junho de 1991, onde seriam eleitas 511 vagas no parlamento, o partido de Advani ganhou, pela primeira vez na História do país, 119 postos, e 20 por cento dos votos. Isto significa que o BJP dobrou sua participação política e 
se tornara o maior partido de oposição. Ainda mais significativo, foi o fato de que o partido ganhou as eleições estaduais e formou governo no estado de Uttar Pradesh - o maior da Índia, à época com mais de 100 milhões de habitantes, e do Gujarat, que detém um dos maiores parques industriais do país.

Em 1992 o governo da Índia, formado pelo partido do Congresso com Narasimha Rao no posto de primeiro ministro buscou resolver a disputa organizando negociações entre o VHP e o Muslim Babri Masjid Action Committee, sem sucesso algum nestas negociações. No início de dezembro, grupos de karsevaks começaram a chegar na cidade. No dia 6 de dezembro de 1992, um grupo com mais de 300 mil pessoas marchou em direção à mesquita e, armados com martelos, machados e pás, literalmente a destruíram. A destruição da mesquita por grupos hindus foi amplamente divulgada pela mídia internacional. O saldo de vítimas fatais, maioria muçulmana, no curso dos eventos que culminaram na destruição da mesquita chegou a 1.700 (Thakur 1993: 645; Jaffrelot 2007: 21).

\section{0 massacre de muçulmanos em Gujarat}

Como mencionado acima, o BJP cresceu substancialmente em um dos estados mais desenvolvidos economicamente na Índia, o estado de Gujarat, situado na fronteira com o Paquistão. Narendra Modi, atual Primeiro Ministro da Índia, foi peça central da investida do BJP na região, sendo governador do Gujarat de 2001 a 2014.

No dia 27 de fevereiro de 2002, o trem Sabarmati Express saiu de Ayodhya, transportando diversos grupos hindus karsevaks que foram prestar apoio à construção do Templo de Rama (até a data presente, fevereiro de 2017, o templo para Rama em Ayodhya ainda não fora construído). Ao passar pela pequena cidade de Godhra, em Gujarat, cidade de maioria muçulmana, dois vagões do trem foram incendiados. Cinquenta e oito passageiros foram vítimas fatais neste incidente, sendo praticamente todos hindus.

Atos de violência sectária são bastante comuns no estado, e poucos imaginavam a amplitude de atos que este incidente viria a disparar. Do incidente com o trem em Godhra seguiu-se uma carnificina sectária no estado de Gujarat sem precedentes. Por quase de quatro meses, dezesseis dos vinte e quatro distritos de Gujarat foram tragados por ondas de violência contra muçulmanos. Particularmente entre os dias 28 de fevereiro e 2 de março, a população da colônia muçulmana de Gulberg, na área leste da capital Ahmadabad sofreu um forte ataque, que fez com que o local deixasse de existir. Somente na tarde do dia 28, setenta e cinco muçulmanos foram assassinados de formas desconcertantemente brutais (Sawant 2002; Yeolekar 2002; Varshney 2002; Nandy 2002; Fachandi 2012), e os sobreviventes deixaram o local, migrando para casa de familiares e amigos, ou para os campos criados para receber deslocados da violência. A capital Ahmedabad sofreu uma onda de migração em massa, e muitos não retornaram até a presente data. A cidade permanece dividida com áreas restritas destinadas à hindus e à muçulmanos. 
Um grupo de civis se organizou com o objetivo de analisar as causas do evento, o chamado Concerned Citizens Tribunal (CCT). Deste relatório, 151 cidades e 993 vilas foram afetadas por tumultos sectários. 0 CTT coletou 2,094 testemunhos de sobreviventes, assim como ouviu grupos de direitos humanos, organizações de mulheres, acadêmicos e ONGs. 0 grupo também teve acesso a documentos produzidos por pessoas que gerenciavam os recém-criados campos de deslocados internos e líderes comunitários; estes documentos possuem listas de pessoas mortas ou desaparecidas, uma catalogação meticulosa sobre as perdas econômicas, e das profanações religiosas. O CCT publicou separadamente estas listas e catálogos, e os deixou anexados ao relatório final. Ademais, mais de uma dúzia de relatos e inquéritos policiais foram deixados nas mãos do CCT, que foram examinados pelos membros do grupo.

O Relatório é aberto com a História da violência sectária no estado de Gujarat. Isso porque os eventos de 2002 fazem parte de um processo longo de disputa entre as duas comunidades religiosas. Principalmente nos anos de 1961-71, especialmente no ano de 1969, mais de 2.000 pessoas, a maioria muçulmanos, perderam a vida em conflitos desta natureza. Exatamente por este motivo, a grande maioria dos envolvidos em esclarecer as razões que culminaram no massacre de 2002 apontam claramente para sua previsibilidade.

Os tumultos de Gujarat são justificados pelos nacionalistas hindus como um ato de retaliação aos muçulmanos que atearam fogo nos vagões do Sabarmati Express. Nos principais jornais da Índia (Times of India e o Hindustan Times), há quem diga que foi um grupo imenso de muçulmanos que atacou o trem; e há quem diga que o evento foi arquitetado pelos próprios extremistas hindus com o intuito de justificar um ataque posterior aos muçulmanos. A causa exata do incidente permanece desconhecida.

De acordo com Praveen Tagodia ${ }^{5}$, secretário nacional do VHP em 2002, a onda de violência pós-Godhra foi uma reação natural aos ataques muçulmanos a diversos peregrinos hindus, e ataques a hindus na Caxemira. Neste período a imprensa local vernácula de Gujarat associava a comunidade muçulmana a terroristas, ao passo que gangues armadas de hindus extremistas se organizavam para dizimar muçulmanos em revanche a tragédia do trem (Yeolekar 2002). De acordo com um pronunciamento público do VHP, a violência em Gujarat foi "a primeira resposta positiva dos hindus ao fundamentalismo muçulmano em 1.000 anos" $^{\prime \prime}$. Esta referência de mil anos se dá exatamente no período de chegada dos muçulmanos na região, período em que ocorreu, segundo os nacionalistas hindus, um longo declínio da civilização hindu. Para os fundamentalistas hindus, o governo de Gujarat fez o que foi eleito para fazer: permitir retaliação violenta contra muçulmanos, mesmo contra milhares de pessoas que nem chegaram perto do incêndio dos vagões de Godhra. 0 saldo de vítimas fatais em quatro meses de violência sectária em Gujarat é de aproximadamente 2.000 pessoas, a maioria muçulmana.

\footnotetext{
${ }^{5}$ Em entrevista ao jornal Times of India do dia 25 de março de 2002.

${ }^{6}$ Publicado no jornal Times of India em 26 de junho de 2002 original: "the first positive response of the Hindus to Muslim fundamentalism in 1.000 years".
} 


\section{A Representação da Comunidade Muçulmana}

Antes mesmo da publicação de Homo Hierarchicus, Dumont anunciou que em sua opinião, as condições perfeitas para o desenvolvimento de uma Sociologia da Índia são encontradas no estabelecimento de uma relação entre a sociologia e a Indologia clássica ${ }^{7}$ (Dumont \& Pocock 1957 p, 02). Por "relação", Dumont segue na esteira de Marcel Mauss, onde a sociedade e a indologia devem ser combinadas, uma vez que o papel da tradição sânscrita demonstra sem sombras de dúvidas a unidade da Índia (p. 04). Esta inferência dumontiana da combinação entre sociologia e indologia como sendo o melhor caminho para uma análise da Índia, tendo a cultura sânscrita como característica universal na região, influenciou - e ainda influencia - diversos cientistas sociais dentro e fora da Índia.

Dumont (2008 [1966]) não trata da presença muçulmana na sociedade indiana, que é entendida como uma sociedade primordialmente hindu. A cultura muçulmana indiana é discutida em Dumont de forma marginal no capítulo X do Homo Hierarchicus, sob o título “Comparação: A Questão da Casta Entre os não-Hindus e Fora da Índia”. Neste capítulo, o foco de Dumont é nos Swat Pathan, habitantes do alto rio Indus (atualmente parte do Paquistão), uma sociedade que sobreviveu isolada da maioria hindu. Se seu foco fosse a sociedade muçulmana dos estados do Punjab, Uttar Pradesh, Gujarat ou das cidades de Mumbai e Deli, ele teria em mãos um material rico, composto por mais de mil anos de interações entre as duas comunidades religiosas.

A concepção hindu, elaborada por Dumont, de que os reis (kshatryia) eram os protetores dos sacerdotes (brâmanes), das vacas e dos templos (DUMONT (2008 [1966]) não pode ser validada se o rei for muçulmano. Portanto, ao discutir as noções hinduístas de parentesco, realeza e domínio em sua análise do sistema de castas, Dumont não considera o fato crucial de que grandes partes da Índia, por mais de seis séculos, estiveram sob o domínio do Império Mughal. É fato consumado de que o Raj britânico influenciou, e modificou, de forma decisiva a sociedade indiana. Curiosamente, na perspectiva de Dumont, o domínio muçulmano parece ter atravessado a Índia por seis séculos sem deixar marcas decisivas na tradição da cultura sânscrita.

As inferências dumontianas ressoam as análises sociais das instituições indianas pós-coloniais. No que diz respeito ás análises sobre violência, o National Crime Records Bureau, é o órgão governamental responsável que, anualmente desde o ano de $1953^{8}$, divulga estatísticas sobre crimes no país, com base nos atos reportados à polícia. 0 Bureau desenvolve diversas seções para analisar crimes específicos, relacionando, de forma inovadora, os crimes às suas vítimas. Este é o caso das seções de "Violência contra as Mulheres", "Violência contra os Dalits", "Violência contra Tribais" e "Violência contra as Crianças". O caráter inovador do Bureau é o de cruzar os dados de crimes com os das vítimas, desenvolvendo o conceito de que há crimes cuja característica é o fato de ter vítimas específicas. Com isso, o Bureau elabora a taxa de incidência dos crimes

\footnotetext{
${ }^{7}$ Indologia é o nome da corrente Orientalista em sua vertente indiana.

${ }^{8}$ www.ncrb.gov.in
} 
considerando o total da população das vítimas. E com isso, contribui para confirmar um fato constantemente ressaltado pela sociologia indiana: as ações sociais se relacionam a predicados, na forma de que todo ato é relacionado a um outrem específico. Esse outrem não é homogêneo, não é aleatório: é mulher, homem ou trans, é membro de alguma casta, subcasta, de alguma religião, seita, fala certa língua, e vem de certa região.

Não há, porém, em nenhuma análise do Bureau, uma seção dedicada a analisar e tratar a violência religiosa. As minorias analisadas pelo Bureau, consideradas vítimas de crimes especificamente voltados contra elas, são as minorias de castas. Minorias religiosas são descartadas da análise. Porém, segundo as mesmas análises do Bureau, a violência coletiva, os riots, são os crimes de maior incidência nos últimos anos. Na maioria destes eventos, a violência coletiva é sectária, num embate entre as duas maiores comunidades religiosas do país. E dentro destas análises, o Bureau não indica quem são as vítimas dos riots, apesar de indicar as vítimas de grande parte dos outros crimes. Nesta perspectiva, o Bureau nos oferece informações de quantos Dalits são vítimas de violência; mas não o número exato de quantos muçulmanos foram vítimas de violência religiosa.

\section{Violência Sectária e o Legado da Partilha}

A história da violência coletiva e sectária na maior parte das análises sociológicas indianas aparece como eventos secundários no curso da História da Índia. As políticas hindus, e as políticas muçulmanas aparecem como elementos menores frente a uma luta unificada e não violenta contra os britânicos; e a violência na maioria dos casos vem associada à mecanismos impostos pela administração colonial. A despeito da formação de dois, e eventualmente três, Estados independentes como resultado da Partilha da Índia, a historiografia, e as ciências sociais indianas tendem a focar no caráter secular e não violento da formação da Índia independente. As ciências sociais optaram por celebrar a independência da Índia como nação soberana, ao invés de lidar com as agonias da Partilha.

Gyan Pandey sugere que a violência religiosa na Índia é tratada como eventos excepcionais, pontos fora da curva, resultados de conjunturas incomuns. Estas análises pretendem dizer que a violência sectária, na quantidade de ocorrências na escala e na frequência desde 1980 ainda não fazem uma diferença fundamental à essência do secularismo das pessoas, e tampouco afetam a tradição nacional de não-violência (Pandey 1992: 41).

O momento da violência e do sofrimento na violência coletiva sectária nos diz muito sobre a condição da sociedade indiana atual. A experiência da violência é uma parte crucial na formação da tradição, do senso de comunidade e da História da Índia contemporânea. As cicatrizes da sociedade ficam claras na divisão identitária pós-colonial extremamente rígida das comunidades hindu, muçulmana e sikh.

Gandhi e o "povo indiano" se tornam símbolos de uma essência nacionalista, de um espírito indiano, que parece ignorar o fato de terem passado por um processo de formação 
onde o auge da luta foi a divisão em dois países em termos religiosos. Nos questionamos se os tumultos sectários a que aludimos não seriam consequências diretas desta História de que pouco se fala.

A Partilha foi para a maioria das pessoas que hoje vivem nos territórios divididos do norte, leste e oeste da Índia, do Paquistão e de Bangladesh, o evento principal do século XX; equivalente em termos de trauma e consequências às Grandes Guerras para a Europa. As experiências da Primeira e da Segunda Guerra são celebradas na Europa com monumentos e eventos nacionais. Não há nada equivalente na Índia. 0 que se celebra na Índia é a conquista da independência por meio da não-violência divulgada por Gandhi, que compõe uma parte muito mínima na composição do que foi a luta pela independência da Índia. 
artigo

\section{Referências}

BRASS, Paul The partition of India and retributive genocide in the Punjab, 1946-47: means, methods, and Purposes. Journal of Genocide Research v. 5, n. 12003

DUMONT, Louis Homo Hierarchicus Edusp, 2008

DUMONT, Louis, POCOCK, David For a Sociology of India. Contributions to Indian Sociology n. 11957

ENGINEER, Ali. Communal Riots in 2002: A Survey. Economic and Political Weekly vol 2 jan 2003

Grim Tragedy of Bhagalpur Riots: Role of Police-Criminal Nexus. Economic and Political Weekly vol 25 n 6 fev. 1990

FACHANDI, Parvis Ghassem. Pogrom in Gujarat: Hindu Nationalism ad Anti-Muslim Violence in India. Princeton University Press 2002

HANSEN, Thomas Blom Wages of Violence: Naming and Identity in Postcolonial Bombay Princeton University Press 2001

JAFFRELOT, Christophe. The Hindu Nationalism: a Reader. Princeton: Princeton University Press, 2007

JOHNSON, Donald JOHNSON, Jean Through Indian Eyes. United Nations: Eyes Book Series 2008.

KHOSLA, Gopal Das Stern Reckoning: A Survey of the Events Leading Up To and Following the Partition of India. Delhi: Oxford University Press, 1989 [1949]

NANDY, Ashis Obituary of a Culture. Seminar, maio, 2002

NEIL, Stewart Divide and Rule: British Policy in Indian History. Science and Society vol 15, jan 1951

PANDEY, Gyanendra In Defence of the Fragment: Writing about Hindu-Muslim Riots in India Today. Representations n.37 jul. 1992

RAI, Satya. Partition of the Punjab: A Study of its Effects on the Politics and Administration of the Punjab 1947-1956. Bombay: Asia, 1967

SAVARKAR, Vinayak Damodar. Essentials of Hindutva. Independent Publish Plataform 2006.

SAWANT, Surej Gujarat in Concerned Tribunal Reports. Ahmedabad 2002

SEN, Amartya. The Argumentative Indian: Writings on Indian History, Culture and Identity. New Delhi: Penguin Books, 2005

SENGUPTA, Roshni Communal Violence in India: Perspectives on Causative Factors. Economic and Political Weekly vol. 40 n. 20 maio, 2005. 
SEE, Sudhir Vyas. Indian Policy, Pseudo Secularism Responsible for Current Crisis. Times of India, 25 de março, 2002

SINGH, Kirpal (ed.) Select Documents on Partition of Punjab. Delhi: National Book Shop, 1991

STEWART, Neil Divide and Rule: British Policy in Indian History Science and Society vol 15 n. 11951

THAKUR, Ramesh Ayhodhya and the Politics of Indis's Secularism: A Double-Standards Discourse. Asian Survey, vol 33, n. 071993

VARSHNEY, Ashutosh. Ethnic Conflict and Civic Life, Hindus and Muslims in India. New Haven: Yale University Press, 2002.

VEER, Van der, Peter. Religious Nationalism: Hindus and Muslims in India. Los Angeles: University of California Press, 1994

YEOLEKAR, Mugdha Gujarat Riots: an Interpretative Analysis. University of Pune, Tese. 2002

\section{Documentos}

Census of India 2011. Disponível em www.censusindia.gov.in

Recalling Bhagalpur: a Report of the Aftermath of the 1989 Riots. People's Union for Democratic Rights Report, PUDR, 1996, disponível em:

http: / / www.unipune.ac.in/snc/cssh/humanrights / 04\%20 COMMUNAL \% 20 RIOTS/A\%20-\%20\%20ANTI-MUSLIM\%20RIOTS/02-BIHAR/02b.pdf

CONCERNED CITIZENS' TRIBUNAL, 2002, “Crime Against Humanity: An Inquiry Into the Carnage in Gujarat", November 21, 2002, Mumbai: Anil Dharkar for Citizens for Justice and Peace, disponível em http://www.sabrang.com/tribunal/. 